\title{
POR UNA EDUCACIÓN PARA TODOS: LAS PERSPECTIVAS FORMATIVAS EN DOS PERIÓDICOS REVOLUCIONARIOS DURANTE LAS PRIMERAS DÉCADAS DEL SIGLO XX
}

\author{
DOI: http://dx.doi.org/10.1590/2236-3459/75709 \\ Eduard Esteban Moreno Trujillo' \\ 'Universidad La Gran Colombia (UGC), Bogotá, Colombia
}

$\cos 80$

\begin{abstract}
Resumen
El objetivo de este texto es realizar un análisis del discurso en torno a la formación de los sectores populares expuesto por dos importantes periódicos radicales de comienzos del siglo XX en Brasil y Colombia. Para el caso Colombiano se aborda el estudio del periódico La Humanidad entre los años 1925 y 1927. Para el caso brasilero se estudia el periódico A Plebe entre 1917 y 1920. Así, en el contexto de una fuerte movilización popular derivada de la cuestión social, además de la párvula constitución del campo de la izquierda local, los intelectuales-populares que escribieron en las páginas de estos periódicos concibieron una educación "racionalista" e inclusiva dirigida a los sectores populares. A partir de la construcción colectiva de un sentido educativo, se compusieron complejos imaginarios sobre el ser obrero y popular, sobre el pasado y el futuro, pero sobre todo, de las lógicas que debían guiar la revolución como un ejercicio formativo. De este modo, el proceso educativo fue concebido como el devenir de la conciencia y el descubrimiento de la verdad "científica". El texto desarrollará cuatro momentos: 1. Los contextos sociales y políticos; 2. Los periódicos como mecanismos de difusión de las ideas; 3 . Los discursos educativos expuestos por los textos; 4 . Finalmente se plantea una suerte de conclusión en torno a los condicionamientos metodológicos de la comparación, y los alcances de los discursos educativos con relación a la práctica de los sujetos y la posible mirada del historiador.
\end{abstract}

Palabras clave: educación, historia comparada, intelectuales-populares, formación libertaria.

\section{POR UMA EDUCAÇÃO PARA TODOS: AS PERSPECTIVAS FORMATIVAS EM DOIS JORNAIS REVOLUCIONÁRIOS DURANTE AS PRIMEIRAS DÉCADAS DO SÉCULO XX}

\begin{abstract}
Resumo
O objetivo do texto é realizar um analise do discurso em torno a formação dos setores populares exposto por dois importantes jornais radicais na virada do século XX em Brasil e na Colômbia. Para o caso colombiano se aborda o estudo do periódico La Humanidad entre os anos 1917 e 1920. Para o caso brasileiro estuda-se o jornal A Plebe entre 1917 e 1920. Assim, no contexto de uma forte mobilização popular derivada da questão social, além da constituição do campo da esquerda local, os intelectuais-populares que escreveram nas páginas destes jornais conceberam uma educação "racionalista" e inclusiva dirigida aos setores populares. Ao partir da construção coletiva de um sentido educativo, compuseram-se intricados imaginários a respeito do ser proletário e popular, sobre o passado e o futuro, mas, sobretudo, das logicas que deveriam guiar a revolução como exercício formativo. De tal modo, o processo educativo foi concebido como o devir da consciência e a descoberta da verdade "cientifica". O texto desenvolverá quatro momentos: 1 . Os contextos sociais e políticos; 2. Os periódicos como mecanismo de difusão das ideias; 3. Os discursos educativos expostos nos jornais; 4 . Finalmente, propunha-se uma conclusão sobre os condicionamentos metodológicos
\end{abstract}


da comparação, assim como dos limites dos discursos educativos frente às práticas dos sujeitos e a mirada do historiador.

Palavras-chave: educação, história comparada, intelectuais-populares, formação libertaria.

\title{
EDUCATION FOR ALL: FORMATIVE PERSPECTIVES IN TWO REVOLUTIONARY NEWSPAPERS DURING THE FIRST DECADES OF THE TWENTIETH CENTURY
}

\begin{abstract}
The objective of this text is to analyze the discourse about the formation of popular sectors exposed by two important radical newspapers of the early twentieth century in Brazil and Colombia. For the Colombian case the study of the newspaper Humanity between the years 1925 and 1927 is approaching. In the Brazilian case the newspaper A Plebe is studied between 1917 and 1920. Thus, in the context of a strong popular mobilization derived from the social question, in addition to the constitution of the field of the local left, the popular intellectuals who wrote in the pages of these newspapers conceived a "rationalist" and inclusive education directed to the popular sectors. For the collective construction of an educational sense, imaginary complexes were built on worker and popular being, on the past and the future, but above all on the logic that should guide the revolution as a formative exercise. In this way, the educational process was conceived as the becoming of consciousness and the discovery of "scientific" truth. The paper will develop four moments: 1 . The social and political contexts; 2 . The newspapers as mechanisms of diffusion of ideas; 3 . The educational discourses exposed by the texts; 4 . Finally, a kind of conclusion about the methodological conditioning of the comparison, and the scope of the educational discourses in relation to the practice of the subjects and the possible view of the historian.

Keywords: education, comparative history, intellectual-popular, libertarian formation.
\end{abstract}

\section{L'ÉDUCATION POUR TOUS: LES PERSPECTIVES DE FORMATION DANS DEUX JOURNAUX RÉVOLUTIONNAIRES AU COURS DES PREMIĖRES DÉCENNIES DU XXE SIÈCLE}

\section{Résumé}

Le but de cet article est d'analyser le discours sur la formation des secteurs populaires exposés par deux journaux radicaux majeurs du début du XXe siècle, au Brésil et en Colombie. Pour l'étude de cas de la Colombie des adresses de l'humanité journal entre 1925 et 1927. Pour le journal brésilien une plèbe cas est étudiée entre 1917 et 1920. Ainsi, dans le contexte d'une forte mobilisation populaire résultant de la question sociale, plus de parvulo à la constitution du champ des intellectuels populaires gauches locaux qui ont écrit dans les pages de ces journaux mis au point un « rationaliste » et l'éducation inclusive destinée aux masses. De la construction collective d'un sens éducatif, complexe imaginaire sur les travailleurs et les personnes se trouvant sur le passé et l'avenir, mais surtout, de la logique qui doit guider la révolution comme un exercice de formation dont ils ont été composés. Ainsi, le processus éducatif a été conçu comme l'évolution de la conscience et la découverte de la vérité "scientifique". Le document développera quatre étapes: 1 . Les contextes sociaux et politiques; 2 . Journaux comme des idées de mécanismes de difusión; 3 . Discours pédagogiques présentés par les textes; 4. Enfin, une sorte de conclusion sur le conditionnement méthodologique de la comparaison, et la portée des discours éducatifs en relation avec la pratique des sujets et la vision possible de l'historien

Mots-clés: education, histoire compare, populaire intellectuelle, formation libertaire. 


\section{Introducción}

- I objetivo de este texto es realizar un análisis del discurso en torno a la formación de los sectores populares expuesto por dos importantes periódicos radicales de comienzos del siglo XX en Brasil y Colombia. Para esto es necesario comprender la forma como los intelectuales-populares ${ }^{1}$ que hicieron posible estos proyectos editoriales entendieron le educación de las masas y su organización. Este ejercicio invita a sumergirnos en una cosmovisión que imaginaba una enseñanza que permitiera romper las estructuras coyunturales para transformar el futuro. De este modo, como una suerte de hipótesis, se puede sostener que durante este contexto histórico la educación fue asumida como un mecanismo indispensable para la trasformación social, ya que esta representaba un dispositivo de concienciación susceptible a resistir ante las lógicas clericales de la instrucción. No obstante, aún quedan algunas preguntas que permiten problematizar este ejercicio: ¿Qué características presentó dicho discurso educativo? ¿Cómo fue su articulación pedagógica y didáctica? ¿Cómo se relacionó lo educativo con lo político-ideológico? ¿Qué sujeto se pretendió formar?

Las preguntas son complejas y su resolución desborda los intereses y límites de este texto. Sin embargo, estos cuestionamientos direccionan de manera implícita las siguientes reflexiones, además de demandar una postura política frente al fenómeno educativo y sus implicaciones al interior del orden social en el periodo histórico propuesto. Atendiendo a esta demanda, asumimos el fenómeno educativo como un ejercicio de reproducción y/o resistencia desde el cual se pueden abrir diversos mecanismos tanto de transformación social como de defensa del statu quo.

Este ejercicio puede ser presentado como un acercamiento descriptivo y comprensivo del pasado, que busca determinar las características de configuración de un discurso político e ideológico que se centró en un imaginario de futuro y en la formación de una nueva imagen de lo popular. Con el fin de enriquecer el ejercicio, se propone la constitución de la mirada desde una perspectiva comparada que busca visibilizar las diferencias y semejanzas de construcciones discursivas que, bajo fines similares, se representaron en contextos sociales y políticos relativamente disímiles. Así, en el marco de estructuras ideológicas de diversa complejidad, pero ancladas en el campo de la izquierda política, se determinaron los diversos mecanismos de educación popular desde los cuales, además, se pretendió crear una "nueva" imagen de los sectores subalternos.

De este modo, al hablar de historia comparada se debe realizar una distinción fundamental para este ejercicio, es la distinción entre el uso del método comparativo en historia y el uso de una perspectiva histórica comparada. (SEWELL, 1967, p. 208-218). Esta distinción es fundamental en tanto determina la rigidez o flexibilidad de los procedimientos metodológicos. Normalmente, cuando se habla de una perspectiva comparada los procesos rígidos que dan cuenta de pasos escrupulosos en la elaboración histórica, pasan a un segundo plano, poniendo sobre la mesa la "creatividad" del historiador para jugar con las escalas y las yuxtaposiciones. De este modo, un estudio con perspectiva histórica

\footnotetext{
${ }^{1}$ La aparición de los intelectuales como movilizadores de ideas se presentó, para el caso de los sujetos aquí estudiados, en el encuentro entre aquellas ideas que develaban la explotación de los sectores subalternos, con las experiencias de resistencias que se agenciaron en el cotidiano. En medio de este ejercicio de mutua afectación, surgió un grupo de individuos que dialécticamente se constituyó en la intelectualidad popular y orgánica de la izquierda de Brasil y Colombia en las primera décadas del siglo XX.
} 
comparada, como el que se propone, no puede ser reducido a una serie de reglas metódicamente utilizadas para solucionar problemas históricos específicos. (SEWELL, 1967, p. 218). Además de permitir un análisis heurístico, la perspectiva comparada posibilita, en términos descriptivos, establecer lógicas de desenvolvimiento a través del contraste de las diversas experiencias. (KOCKA, 2003, p. 40).

Por otro lado, el análisis de las ideas educativas se aborda desde las posibilidades que brinda la historia social de las ideas. Esta perspectiva implica comprender los procesos de apropiación social de las ideas con el fin de "seguir al pensamiento por toda la fábrica social". (DARNTON, 2010, p. 50). Así, en lugar de concentrar la mirada sobre un "espíritu trascendente y creador", el análisis trasciende a la ideología de cierto grupo social, desde la cual se pueda "recrear el lenguaje político" (DARNTON, 2010, p. 51) en el que se pusieron en juego la interpretación del presente y los diversos futuros posibles. En este punto sobresale el estudio de las manera como los sectores populares comprendieron su mundo y expresaron ciertas formas de autoformación, a partir de la apropiación de las ideas que conformaron el campo de la izquierda.

Las fuentes en las que se basa este texto son los periódicos A Plebe de São Paulo, especialmente en su primera etapa de publicación que fue de 1917 a 1927, y el periódico La Humanidad de Cali, entre los años 1925 a 1927. La elección de estos periódicos corresponde a dos criterios: En primer lugar, estas publicaciones ejercieron un impacto importante al interior de los sectores populares y obreros a los cuales se dirigían, esto se debió a su amplia divulgación y reconocimiento como mecanismos de circulación de las ideas de izquierda. El segundo criterio de selección consistió en la accesibilidad real a dichas fuentes. En el caso del periódico La Humanidad solo se conservan los 100 números que comprenden los años que se proponen para el estudio. Por el contrario, del periódico A Plebe se conocen todos sus números desde 1917 hasta 1949.

Los límites temporales obedecen a las coyunturas disímiles en las que las ideas de izquierda y la movilización social estuvieron en auge. Mientras que en Brasil, especialmente en São Paulo, como lo veremos más adelante, se vivió un importante periodo de movilización y circulación de las ideas entre 1917 y 1920, en Colombia el periodo de mayor auge social y político durante las primeras décadas del siglo XX se dio entre 1925 y 1930. Estos periodos respondieron a la convergencia de múltiples factores sociales, políticos, económicos y culturales, que hicieron posibles que los sectores populares, en el marco de la adhesión a un movimiento político-ideológico de izquierda, representaran una concepción particular de educación.

\section{El poder de las elites y los contextos sociopolíticos}

El desarrollo precario del sistema capitalista periférico en América Latina articuló las condiciones para el surgimiento del campo de la izquierda como espacio ideológico opuesto al statu quo que imponían las elites gobernantes. Campo que a su vez estableció las condiciones de posibilidad para la gestación de movimientos, grupos, organizaciones y partidos políticos que pretendieron representar y defender a la clase obrera y a los sectores populares en su condición de colectivos explotados. Así, al interior de un malformado y precoz sistema capitalista, se configuró un campo político-ideológico con sus propias reglas de juego y sus propios intereses formativos.

El campo de la izquierda se organizó paulatinamente con el avance de las 
transformaciones capitalistas en el interior de sociedades predominantemente agrarias, en las que las prácticas e instituciones políticas se modelaron con el fin de naturalizar la visión de una oligarquía que creía encarnar el espíritu de la nación. Durante las dos últimas décadas del siglo XIX y las primeras tres décadas del siglo XX, Brasil y Colombia atravesaron, cada uno a su modo, por un periodo que determinó la naturalización de ejercicios políticos en los que "la doctrina de los chefes naturais" fue la regla general.

Entre 1889 y 1930 Brasil estableció una "Republica oligárquica" caracterizada por la hegemonía de una clase social de grandes señores de la tierra, fuertemente influenciados por un "liberalismo elitista". (FAUSTO, 1989, p. 8). Después del 15 de Noviembre de 1889, con la caída del Imperio, y pasado el corto periodo denominado "encilhamento" (18891891), en el que se incentivó la industrialización interna, la Republica encarnó un "misto de nepotismo, compadrio e, ao mesmo tempo, furor republicano [que substituiu] o antigo sistema do patronato imperial". (CARDOSO, 1989, p. 39). Este sistema, predominante durante la Primera República, se estableció sobre un "pacto oligárquico" que permitió a la elite exportadora de café consolidar su poder en el plano nacional, a pesar de no contar con un partido político único nacional que articulara los niveles locales con la federación. Este esquema fortificó la autoridad presidencial en cambio de la libertad de acción de los gobernadores de Estados - especialmente de los Estados más "importantes". (WIRTH, 1989, p. 91). De esta manera, según el sociólogo Fernando Henrique Cardoso, el equilibrio entre los poderes de la Republica pasó a depender de una voluntad directora que tuvo sus "bases naturais" en la violencia local y la transacción entre las maquinas políticoadministrativas de los Estados y los intereses político-económicos de los dueños de tierras y de votos. (CARDOSO, 1989, p. 49).

Finalmente, la hegemonía de la elite exportadora de café fue ratificada después de 1906, cuando el gobierno federal implemento un esquema de valorización artificial del café sustentado por São Paulo, que acentuó las desigualdades regionales y promovió la identificación entre los intereses cafeteros y el interés nacional. De ese modo, durante la Primera República, el sistema político brasilero se consolidó bajo el marco de las relaciones de poder de las diversas oligarquías regionales, dentro de las cuales la oligarquía paulista ejerció una función hegemónica, a partir de su alianza con la oligarquía minera. (FAUSTO, 1989, p. 145).

Un epifenómeno político y social de este sistema, en el que se enmarcaron las relaciones de poder oligárquico, fue el coronelismo ${ }^{2}$. Como resultado de las relaciones de poder en las que se combinaron intereses económicos específicos con las intenciones de consolidar la Republica a partir de la articulación de los niveles local, regional y nacional, el coronelismo representó un esquema de acción política que, siguiendo al profesor José Murilho de Carvalho (1997), puede ser definido como "um sistema político, uma complexa rede de relações que vai desde o coronel até o presidente da República, envolvendo compromissos recíprocos". Sistema que, además, pretendía adaptar el poder privado de una elite local, que controlaba el poder económico y social, a un régimen político de extensa base representativa. (QUEIROZ, 1989, p. 157).

Aunque no se puede sostener que haya existido un tipo único de Coronel en todo el territorio brasilero, en sus rasgos generales este individuo de la elite encarnó, a partir de

2 Cf: Leal, 1948, 1980; Carvalho, 1997; Queiroz, 1989; Carone, 1975. 
la proclamación de la Republica, lo que fuera el "mandonismo local"3 de periodos anteriores. Así, el coronelismo representó un tipo de relaciones de poder excluyente, que se cimentó en antiguas relaciones de "parentesco" en las que el Coronel, como punto de referencia de la estructura social rural, se aseguraba la lealtad de su parentela ${ }^{4}$ de nivel económico inferior, por medio de favores políticos y/o económicos. Progresivamente, como explica Isaura Pereira De Queiroz, a partir de la reciprocidad de dones y contra-dones dentro de la parentela, la causa de un jefe se constituía en la causa de los mandados, estableciendo así, una solidaridad mutua entre los coroneles y sus bases sociales inferiores. (QUEIROZ, 1989, p. 163).

Sin embargo, este sistema en torno al cual circuló el poder en Brasil al comenzar el siglo XX, y que descansó en la hegemonía de la oligarquía exportadora de café, empezó a dar muestras de cansancio. Debido a que fue un sistema heredado de las lógicas sociopolíticas de la colonia y el imperio ${ }^{5}$, su línea de progreso durante la Republica descendió a medida que las relaciones capitalistas se acentuaron con más fuerza, y la nueva sociedad de masas hacia su aparición. Con el surgimiento de la ciudad industrial, el crecimiento de la fuerza de trabajo asalariada, y la clara separación entre la elite y el pueblo que se presentó en las ciudades, las solidaridades que el coronel construyó con su clientela se resquebrajaron progresivamente. De esta manera, siguiendo la propuesta de Queiroz, la "solidaridad vertical" del coronelismo le dio paso a una "solidaridad horizontal" en la que cada grupo social se solidarizó con sus semejantes, hasta entrar en pugna abierta con otras grupos sociales "superiores" o "inferiores". (QUEIROZ, 1989, p. 182).

Si bien, entre 1889 y 1930 Brasil se sumergió en una Republica Oligárquica en la que una elite económica intentó transformar su ideal particular de Nación en un ideal colectivo, esta práctica hegemónica no se distanció de las realidades de las naciones vecinas. Colombia, durante el mismo periodo, fue escenario de una Republica Conservadora en la que el poder de un sector de la elite gobernante se sustentó en la "coacción electoral" y la influencia del clero para limitar el voto de una supuesta oposición política. (CARBÓ, 2002, p. 33). El periodo político que va de 1886 a 1930 fue "bautizado" por la historiografía nacional, como "la hegemonía conservadora". Este periodo encarnó un proceso político fragmentado, cargado de sectarismo e intolerancia partidista.

En 1886 el periodo se inauguró con una coalición de facciones afines entre el Partido Liberal y el Partido Conservador, que tuvo como objetivo la proclamación de una nueva constitución política que pusiera fin a un periodo de federalismo radical. Con el lema "Regeneración o catástrofe" el político liberal del ala independiente Rafael Núñez, con el apoyo del conservadurismo, asumió la presidencia de la república en 1884 e inicio un

\footnotetext{
${ }^{3}$ De acuerdo con la socióloga María Isaura Pereira de Queiroz, el mandonismo local brasileiro fue un rasgo de la estructura socioeconómica tradicional del país, y que se fundamentaba "em grupos de parentela que são ao mesmo tempo grupos de parentesco de sangue com suas alianças, e grupos de associados econômico-políticos". (QUEIROZ, 1989, p. 159).

${ }^{4}$ Maria Isaura Pereira de Queiroz define la parentela como: "um grupo de parentesco de sangue formado por várias famílias nucleares e algumas famílias grandes [...], vivendo cada qual em sua moradia, regra geral economicamente independentes; as famílias podem se encontrar dispersas a grandes distâncias umas das outras [...]. Sua característica principal é a estrutura interna complexa, que tanto pode ser de tipo igualitário [...], quanto de tipo estratificado [...]. Fosse igualitária ou estratificada, a parentela apresentava forte solidariedade horizontal, no primeiro caso, vertical e horizontal no segundo, unindo tanto os indivíduos da mesma categoria, quanto os indivíduos de níveis socioeconômicos diversos". (QUEIROZ, 1989, p. 165).

${ }^{5}$ Sobre la continuidad de estas relaciones ver las propuestas ya citadas de Basbaum (1976); Queiroz (1989).
} 
proceso de regeneración que paulatinamente termino siendo netamente conservador. La constitución del 1886, promulgada por su gobierno, se caracterizó por amparar un rígido centralismo que defendía el autoritarismo presidencial y limitaba los derechos individuales, además de implantar un sistema electoral destinado a conservar el poder en manos de una restringida clase dirigente. (MELO, 1996, p. 53). Bajo esta perspectiva, una consecuencia directa de este proceso de centralización, y siguiendo al profesor Jorge Orlando Melo, fue la ampliación de los conflictos bélicos al ámbito nacional. La violencia se estableció como el mecanismo de control predilecto en el escenario político nacional. En términos económicos la Regeneración criticó la tradición política del libre cambio y, a través del manejo fiscal, activó una política proteccionista de la manufactura nacional, lo que impulso precariamente el mercado interno. (MELO, 1996, p. 53).

Uno de los aspectos más significativos de este proceso fue el "nuevo" acuerdo al que llegaron los dirigentes del Estado con la Iglesia. Con la firma del Concordato (1887), en donde se le entregó - de nuevo - el poder educativo y cultural a la Iglesia, el país ingresó en una era que coronó, a partir de la lucha política de las diversas facciones de la elite, a la violencia y al sectarismo como elemento constitutivo del proceso político colombiano. La iglesia se convirtió en un poder central en la política y la vida social del país bajo este contexto ${ }^{6}$. No por acaso, la constitución fue declarada en "nombre de Dios, fuente suprema de toda autoridad".

Durante los 44 años que componen este periodo, se configuraron los actores y los conflictos sociales y políticos que, de acuerdo con el historiador colombiano Carlos Medina Gallego, determinaron el rumbo histórico de todo el siglo XX colombiano. (MEDINA, G., 2011, p. 34). A diferencia de Brasil, los partidos políticos hegemónicos en Colombia no llegaron a representar, durante estos años, un interés económico de clase claramente identificable. Así, la pertenencia a un partido era, sobre todo, cuestión de origen familiar, o de nacimiento en una determinada localidad, lo cual se reforzaba por la condición religiosa. (MELO, 1996, p. 105). Los partidos Liberal y Conservador fueron partidos "pluriclasistas", dentro de los cuales convergieron intereses de todo tipo. Fenómeno que puede explicar, en parte, la razón por la cual el bipartidismo sobrevivió en Colombia durante todo el siglo XX. (TIRADO, 1996, p. 103).

El bipartidismo colombiano delineó un contexto en el que el sistema político cerró la puerta a cualquier elemento ajeno a la elite burocrática para acceder a las instancias del Estado. Este sistema oligárquico visaba el control de los aparatos del Estado por medio de facciones internas dentro de los partidos políticos que, en una especie de puesta en escena política y "democrática", fingían disputar el poder entre dos visiones de Estado aparentemente opuestas. No obstante, siempre que las elites liberales y conservadoras veían que su posición social era puesta en peligro por alas más radicales de sus propios partidos, la unión entre ellos no se hacía esperar, de esta forma retomaban el poder y continuaban con su parodia política.

Sin embargo, la puesta en escena de intrigas y conjuras políticas entre la elite, no redujo el impacto de sus luchas al escenario político. Por lo contrario, y como herencia del

\footnotetext{
${ }^{6}$ De acuerdo con los profesores Renán y Aguilera, "La Iglesia como institución llegó incluso a disponer el tipo de estética que podría circular en el país [durante la época], fomento la presentación de obras de teatro de tipo religioso y prohibió obras clásicas de teatro universal por considerarlas sacrílegas y atentatorias contra las buenas costumbres y la moral cristiana". (AGUILERA; VEGA, 1998, p. 156).
} 
periodo de independencia, la guerra era vista como un medio común y fácil para continuar las disputas por el poder. Ejercicio, este último, que se agravaba con la participación de las masas campesinas quienes, por múltiples razones, participaban en las disputas haciendo parte de ejércitos privados que defendía una u otra perspectiva.

Entre 1899 y 1902 Colombia vivió una de sus guerras civiles más cruentas, en las que se contaron más de 100.000 muertos?. "La Guerra de los Mil días" fue protagonizada por un grupo de Liberales Guerreristas contra el Estado Conservador. Además del desangramiento interno y el agravamiento de la crisis económica y social, la consecuencia más comprometedora de la guerra fratricida fue la perdida de Panamá. Estimulada por los círculos imperialistas norteamericanos, quienes tenían interés en la construcción de un canal interoceánico, y ante la indiferencia de la oligarquía nacional, que se encontraba sumida en sus odios mutuos, Panamá exigió su independencia de Colombia en 1903. Las elites, sin distinciones de partido, quedaron perplejas ante la pérdida de territorio colombiano. De ahí en adelante floreció un "clima de entendimiento" sobre las bases de un nacionalismo conservador que abogaba por una vuelta a los fundamentos hispánicos de la Nación ${ }^{8}$. Bajo la fuerza de los hechos, las elites comprendieron que debían asegurar una relativa estabilidad política con el fin de alcanzar la inserción al sistema económico mundial, y garantizar el respeto de los estados vecinos.

A diferencia de lo que ocurrió en Brasil, en Colombia la construcción de solidaridades horizontales no llevo a la "rápida" constitución de una pugna de "clase contra clase" que permitiese el surgimiento de grupos sociales reivindicatorios de las clases populares y de los primeros grupos obreros que se conformaban. Por lo contrario, y debido al prolongado desacuerdo entre las elites, y al evidente alejamiento del Partido Liberal del poder, el discurso de este partido político fue atrayendo el inconformismo de las clases populares, reduciendo así el espacio para la aparición de terceros partidos que reivindicaran los sectores subalternos.

En términos ideológicos la Regeneración, y enseguida la hegemonía conservadora, constituyeron un sistema social basado en una "ideología religiosa, en la exclusión de los contrarios políticos y en la persecución de todo lo que pudiera ser visto como protesta social". (AGUILERA; VEGA, 1998, p. 151). El espíritu de la época, comandado por la elite en el poder, representó la antítesis del espíritu de modernidad que conocía el mundo. Desconociendo el papel modernizador que desempeñaron el utilitarismo, el positivismo, el romanticismo y el socialismo como ajes de la modernidad, la principal obsesión de los letrados dirigentes de la época fue la de preparar buenos cristianos. La idea de buen cristiano se opuso a la de ciudadano como entidad rectora del Estado.

De esta manera, ya sea por la alianza silenciosa de la elite en el poder, como en el caso brasilero, o por la pugna fratricida entre la elite, como en Colombia, las condiciones de posibilidad de un discurso educativo desde los sectores populares fue perseguida.

\footnotetext{
7 De acuerdo con Jorge Orlando Melo, la Guerra de los Mil días "sería la más violenta y prolongada de la historia colombiana: en ella se volvieron a ver los familiares reclutamientos forzosos, la expropiación de bienes, los empréstitos obligatorios a cargo de los enemigos del régimen, y la muerte de un elevado número de colombianos: las cifras de bajas de la guerra han girado alrededor de los 100.000 muertos, número sin duda exagerado, pero que indica la magnitud de la violencia". (MELO, 1996, p. 56).

8 Esta vuelta a los fundamentos hispánicos ratificó la visión conservadora y clerical del Estado y las elites, la cuales argumentaron la necesidad de "unidad patricia" a partir del rescate de la herencia hispana, que era vista como un bien común para la nación.
} 
Cualquier posibilidad política e ideológica que disputara el poder de las elites, era atacada. No obstante, estos contextos marcados por el elitismo y la represión, también determinaron acciones de resistencia representadas en los periódicos radicales y populares. Los periódicos se constituyeron como espacios de libertad en los cuales los sectores populares, por medio de sus intelectuales, reclamaron su capacidad para soñar nuevos mundos posibles. (GONÇALVES, 2004; SANTOS, 2013; MORENO, 2017). De este modo, los periódicos radicales se configuraron e un proyecto educativo. "Tal como a escola, a imprensa anarquista veiculava saberes e aciona estratégias de divulgação e assimilação desses saberes, tais como: bibliotecas, conferências, escolas, centros de estudos sociais, sindicatos etc.; ou seja, encetava ações que ratificam o jornal como um instrumento de educação informal por excelência". (GONÇALVES, 2004, p. 1).

\section{Los periódicos radicales como mecanismos de difusión de las ideas populares}

En medio de este complejo escenario de castración social por parte de las élites gobernantes, los periódicos radicales surgieron en medio de fuertes agitaciones populares para convertirse en portavoces de la resistencia y de las nuevas ideas libertarias que se esparcían como pólvora por el mundo. Si bien los niveles de alfabetización tanto de Brasil como de Colombia al comenzar el siglo XX no fueron altos, los periódicos populares de izquierda o radicales se convirtieron en mecanismos de socialización de las ideas y del ejercicio educativo. Ya fuera por su lectura silenciosa, o en la voz de alguno de los compañeros que sabían leer, los periódicos cumplieron un papel determinante en la configuración de una cultura de izquierda, además de ser un artefacto eficaz de educación popular al interior de los centros de trabajo.

Tanto A Plebe como La Humanidad agenciaron mecanismos de resistencia por medio de los cuales los sectores populares contrarrestaron, de algún modo, los discursos, imaginarios y representaciones que las elites construían sobre ellos. En este sentido, los procesos educativos inmersos en los planes revolucionarios que direccionaron los periódicos fueron asumidos como oportunidades de resistencia a partir de la creación de una cultura popular autónoma.

Como principio unificador de las intencionalidades educativas, se puede sostener que los dos periódicos se desarrollaron en el marco de la dialogicidad como sistema de intercambio interestructurante. Esto quiere decir que el sentido de difusión de los periódicos se basó en un constante dialogo entre líderes populares de diversos países y regiones. Condición que hizo posible la convergencia de un sin número de cosmovisiones enmarcadas en las lógicas de la revolución futura y la formación de un hombre nuevo. La educación como ejercicio de resistencia y búsqueda de la autonomía se configuró bajo un prisma colorido, en la que esta fue asumida como un ejercicio de empoderamiento popular; pero también como un mecanismo disciplinamiento moral y revolucionario que buscaba crear nuevas prácticas entre los sectores desposeídos, sin desconocer la diversidad cultural que los albergaba.

En el caso de $A$ Plebe, se establecieron prolíficas discusiones e intercambios entre su director, el paulista Edgar Leuenroth (Mogi Mirim, 31 de octubre de 1881 - São Paulo, 28 de septiembre de 1968), e importantes personajes de la militancia anarquista europea y 
local como Neno Vasco ${ }^{9}$, Gigi Damiani ${ }^{10}$ y Benjamin Motta ${ }^{11}$. En el periódico La Humanidad, bajo la dirección de Ignacio Torres Giraldo (Filandia, Quindío el 5 de marzo de 1893 - Cali, 15 de noviembre de 1968), participaron diversos líderes que, ya fuera por su condición social o por su autodidactismo, tuvieron la posibilidad de vivir numerosas experiencias de resistencia a nivel local y global. Entre ellos estuvieron el militante griego Evaristo Priftis, quien antes de arribar a suelo Colombiano había pasado por Argentina, Chile, Bolivia, Perú y Ecuador (ARCHILA, 1985, p. 33), y el Medico e intelectual colombiano Neftalí Arce, quien estudio en Paris donde conoció las ideas de izquierda, especialmente las de Marx, además de conocer, de primera mano, los acontecimientos revolucionarios que se vivían en Europa.

Esta característica nos permite hablar de periódicos populares con pretensiones educativas cosmopolitas, ya que la intención de sus colaboradores fue la de poner en práctica las ideas de la educación moderna, y con ello hicieron referencia a la educación racionalista y al legado de Francisco Ferrer. Para estos periódicos el pueblo debía, en primer lugar, conocer el devenir de los acontecimientos revolucionarios que se estaban presentando en el exterior. La educación pasaba por el ejemplo rector y la asimilación de las experiencias de resistencia lejanas. De este modo, en el marco de una compleja configuración del campo de la izquierda local, la concepción del proceso educativo se desenvolvió en una dialéctica que iba del respeto a la idiosincrasia local, hasta el reconocimiento de la universalidad de la revolución debido a la coyuntura histórica.

Así, los periódicos abrieron la posibilidad para que las ideas que estaban transformando al mundo hicieran su ingreso a los espacios de socialización de los sectores populares, resquebrajando, en alguna medida, el poder cultural de la iglesia y la represión de las elites. Bajo esta perspectiva, la tarea primordial consistió en crear signos distintivos que hicieran posible el auto-reconocimiento de los sectores subalternos, para lo cual, además de desarrollar el orden de un discurso particular y de promover constantemente la lectura, los periódicos propusieron una educación iconográfica por medio de la cual el lector se podía sentir identificado como un actor importante en el escenario social. De este modo, especialmente en $A$ Plebe, el periódico constituyó diversas herramientas, que se podrían asumir como didácticas ${ }^{12}$, por medio de las cuales el lector podía acercarse a su realidad y

9 Vasco llegó por primera vez al Brasil a la edad de 8 años con su padre y su madrastra. Algunos años después
regreso a Portugal para culminar su formación académica. Después de obtener el título de abogado en la
Universidad de Coimbra, lugar donde además dio sus primeros pasos en la militancia libertaria, a finales de
1901 retorno a Brasil en donde experimentó una década de ardua militancia y promoción de las ideas de
izquierda que cultivo progresivamente. Debido a su relación con los inmigrantes italianos en São Paulo,
Vasco entró en contacto cercano con la obra de Errico Malatesta y se alineó con sus concepciones sobre la
organización obrera.
10 Después de algunos años de rebeldía y lucha libertaria, Damiani llego a Brasil en 1897 , y regreso a Italia,
tras ser expulsado en 1919 . Tras su regreso a Italia Damiani se convirtió en el compañero de ruta de Errico
Malatesta al colaborar y dirigir el periódico Umanita Nova.
11 Como masón y militante anarquista, Mota fundo, en 1901 , el periódico A Lanterna con un claro sentido
anticlerical. Sin embargo, la crítica siempre fue más allá de los abusos de poder de la Iglesia. El Estado y la
sociedad burguesa de inicios de siglo, también fueron objetivo de crítica constante por parte de esta
publicación. Su pluralidad temática posibilitó que el periódico fuera leído por una amplia gama de la
población, que veía en $A$ Lanterna una opción de información crítica con la cual no contaban. En el camino
que llevo al surgimiento de $A$ Plebe, como continuación de $A$ Lanterna, el periódico se convirtió en un espacio
de convergencia y afinidad política desde el cual se impulsó la solidaridad y la lucha por la libertad de los
individuos. La figura de Mota permite articular el ejercicio de la crítica a las condiciones existentes en la
época, con la pretensión de divulgación de las ideas y formación, presente en las acciones de los
intelectuales de izquierda.
12 Más adelante veremos que estas "didácticas" fueron una preocupación que se desarrollaron de manera 
a su destinó marcado por la revolución social.

En La Humanidad el uso de la imagen no fue tan recurrente como en el caso brasilero. Esta particularidad pudo haber respondido a dos fenómenos. Por un lado a la precariedad de las imprentas y tipografías que se pudieron utilizar casi de manera clandestina en Colombia, ya que muchas de estas máquinas eran de construcción semiartesanal. (NUÑEZ, 2006, p. 37). Otro factor pudo obedecer a un afán por la erudición, que se hizo evidente en un discurso excesivamente retorico y barroco. No obstante, se pueden encontrar algunas imágenes que acompañaron los discursos educativos, en ellas sobresalieron las figuras de importantes líderes de la izquierda nacional e internacional, y su ensalzamiento como héroes sociales.

Detrás del uso de recursos literarios y pictóricos, los periódicos tenían como objetivo hacer que sus lectores -o posibles lectores-, tomaran conciencias de su condición de explotados, inscribiendo su discurso en el marco de una corriente político-ideológica particular. En el caso de A Plebe, su discurso se basó en los postulados anarquistas, y desde esa perspectiva la imagen de sujeto que pretendió formar a través de sus páginas fue la de un hombre libre. Y para esto debía liberarse del moralismo cristiano y comprometerse con una moral otra basada en la camaradería, la hermandad y la razón.

El periódico La Humanidad se constituyó a partir de múltiples referentes ideológicos que respondieron, en primer lugar, a sus luchas cotidianas. Así, entre sus influencias estaba el anticlericalismo y el anticonservadurismo como mecanismos de resistencia frente a los entes que poseían el monopolio del poder político y cultural en el momento. También se pueden identificar ideologías políticas más definidas como la tradición radical heredada de la Revolución Francesa, tradición que venía de la lucha de los sectores artesanales, así como de las lecturas que se hicieron de los acontecimientos de la Comuna de París y, obviamente, de la Revolución Rusa. Toda esta influencia encarnó una perspectiva de educación más ecléctica. La imagen de los sectores populares que pretendió crear fue la de su condición de productores de riqueza y como los verdaderos representantes de la patria. Una patria que debía ser superior a los partidos políticos tradicionales.

Se podría decir, entonces, siguiendo al sociólogo Guillermo Sunkel (1987) y a la profesora Luz Ángela Núñez (2006), que los periódicos intentaron reproducir una "matriz cultural" de lo popular basada en dos relaciones. Por un lado una idea de lo simbólicodramático, caracterizada por el uso de un "lenguaje dicotómico concreto y de imágenes, derivado de una concepción religiosa del mundo". (NÚÑEZ, 2006, p. XXIX). Por otro lado, la matriz racional-iluminista, la cual se expresó "a través de un lenguaje abstracto y conceptual que está regido por el mecanismo de la generalización”. (SUNKEL, 1987, p. 3). Desde esta perspectiva, se comprende la convergencia, aparentemente contradictoria, entre un discurso educativo cargado de resistencia frente a los poderes del capitalismo, y un disciplinamiento moral con pretensiones iluministas.

Por otro lado, los periódicos agenciaron una ruptura importante en la relación Estado-Iglesia. De una manera más radical, el periódico paulista atacó a la iglesia y al Estado como sostenedoras de la represión. Las ideas que $A$ Plebe puso en circulación se concentraron en incentivar la autonomía popular y la ruptura con una iglesia que asumieron como un elemento "pernicioso, aliado perenne dos dominantes [...]" (A PLEBE, $n^{\circ}$ 1,

diversa al interior de los periódicos, siendo en algunos más explícito que en otros. 
09/06/1917). Para A Plebe el Estado y la iglesia estaban "Associados no mal” por eso sería infructuoso separarlos:

pois que a sua condicao de existencia está indissoluvelmente ligada á propia uniao, que lhes asegura a situacao revoltante de dominadoras moraes e materiaes de toda a sociedade humana, que vive tyrannizada e espoliada afim de lhes garantir vida farta, ociosa e perarsitaria. (A PLEBE, $n^{\circ} 1,09 / 06 / 1917$ ).

En el periódico colombiano La Humanidad los ataques a la iglesia y el Estado fueron sopesados por dos factores: En primer lugar, el discurso orientador del periódico intentó no reñir con las creencias religiosas extremadamente arraigadas en los sectores populares. Por distintas razones culturales, sociales y económicas, la sociedad colombiana de la época, mayoritariamente campesina y sumergida en un provincianismo pasmoso, desarrolló un vínculo muy fuerte con la fe católica y las directrices eclesiásticas. Esta característica no podía ser ignorada por los periódicos. De hecho, muchos de los "obreros ilustrados" o intelectuales populares que hicieron posible la aparición de este tipo de periódicos creían y se apropiaron de este discurso de fe. De este modo, en un manifiesto para los trabajadores publicado en 1927, al explicar el socialismo, el periódico se refiere a esta ideología como "la herencia de todos los martirios", ya que "todo lo bueno que soñaron las religiones, buscó la encarnación en el ideal de los oprimidos"; y continúa: "Difícilmente hallamos un apostrofe contra los verdugos del pueblo, contra los escribas y fariseos, que no esté consagrado en los Evangelios de Jesús [...]" (LA HUMANIDAD, n 89, 27/08/1927).

El segundo factor que reguló los ataques del periódico La Humanidad hacia el Estado pasó por la crítica al poder que tenían los partidos políticos tradicionales. La intencionalidad del periódico fue la superación de las pasiones políticas por parte de los sectores populares, quienes eran los más afectados por las disputas entre las elites y sus respectivos partidos políticos. En el discurso ofrecido por el periódico se asumió que la distinción entre el partido Liberal y el Conservador era engañosa: "[...] el pueblo colombiano es víctima de una coalición hibrida de todos los rezagos coloniales, manejados y explotados hábilmente por una burguesía bicolor". (LA HUMANIDAD, n 32, 22/12/1925).

Otra función importante que cumplieron los periódicos populares consistió en incentivar un principio de racionalidad que entró en pugna con las viejas creencias, y determinó la manera como fue comprendido el ejercicio educativo. Este privilegio de la razón se apoyó en dos fenómenos: En primer lugar, el papel de la ciencia como debeladora de la "verdad" y el progreso social y técnico. En segundo lugar, se afirmó en el devenir histórico, traducido en los acontecimientos revolucionarios por los cuales estaba pasando el mundo europeo durante las primeras décadas del siglo XX. Desde esta perspectiva la razón fue asumida como el devenir lógico de los hechos sociales. Así, se incentivó el estudio de la realidad a partir de los hechos sociales concretos. (LEUENROTH, [1919], p. 13).

Sin embargo, el uso de la razón como un elemento justificador del discurso político y pedagógico no significó la negación de un lenguaje que privilegió lo fantasioso e imaginario para acercarse a lo popular. En el caso de La Humanidad, por ejemplo, la razón fue asumida como una diosa que privilegiaba el amor al prójimo:

[...] Y porque tenemos amor al humano linaje y porque tenemos el sentido de la lógica en el templo de la diosa Razón, es que absolvemos a todos los sindicados de pecado en la senda de la vida!!! (LA HUMANIDAD, $\left.n^{\circ} 8,04 / 07 / 1925\right)$. 
Finalmente, la prensa radical agenció mecanismos que, de algún modo, hicieron más democrático el ejercicio educativo. Si bien, la educación ofrecida por medio de este tipo de publicaciones no brindaba la posibilidad de otorgar "títulos de distinción" como la educación formal, ya fuera la brindada por el Estado o por la Iglesia, sí ofreció los medios informativos y de sociabilidad intelectual que posibilitaron la acumulación de capital simbólico y cultural entre sus colaboradores y lectores, es decir, al interior del campo de la izquierda, y a través de lo que Darnton (2010) llama el andamiaje social. En este sentido, y siguiendo un poco la matriz de una historia social de las ideas, los periódicos radicales vehicularon saberes que se pudieron filtrar en los espacios más íntimos de los sectores populares. Las ideas se despojaron de los reparos academicistas para posarse en la cotidianidad de los sujetos. Podríamos decir que la idea educativa se instauró bajo el ritmo de la cotidianidad popular.

\section{Los discursos educativos expuestos por los textos}

De entrada se puede afirmar que tanto A Plebe como La Humanidad asumieron la educación como un ejercicio de concienciación, autodeterminación y empoderamiento popular, que tuvo como objetivo la formación de hombres libres. De esta manera, los periódicos replicaron discursos que reivindicaron una educación racionalista, desde la cual se pudiera instaurar una nueva cultura popular, que hiciera resistencia a las miradas peyorativas que las élites lanzaban sobre los sectores excluidos. Así, en los periódicos había una estructura de pensamiento libertario que anticipó una concepción educativa en la que el educador, en este caso el intelectual-popular, puede ser asumido como un "profesor-intelectual" capaz de "plantear cuestiones serias acerca de lo que ellos mismos enseñan, sobre la forma en que deben enseñarlo y sobre los objetivos generales que persiguen. (GIROUX, 1990, p. 171). El objetivo fue crear una imagen de lo popular basada en la resistencia y las posibilidades de transformación social. Además, se encuentra con facilidad una idea de educación como praxis, reflexión y acción del hombre sobre el mundo para transformarlo. (FREIRE, 2011). De esta manera, nos topamos con el germen de una educación popular contradictoria que, entendiendo las condiciones históricas de su planteamiento, intentó alcanzar la emancipación social desde el disciplinamiento moral.

En el caso de $A$ Plebe la racionalidad fue un elemento fundamental. Guiados por los preceptos del pedagogo español Francisco Ferrer ${ }^{13}$, el racionalismo consistió en educar sin "preconceito" ni dogmatismo. El periódico instó a educar en el amor, el bien y la justicia. (A PLEBE, no 13, 08/09/1917). La racionalidad educativa fue asumida como conciencia, ya que el hombre debía ser educado para revelarse contra el látigo del señor. (A PLEBE, $n^{\circ}$ 13, 08/09/1917). En la misma línea, la función de la ciencia consistió en dotar a los hombres de capacidad para tomar decisiones de manera autónoma, basados en la verdad que traían consigo los acontecimientos sociales.

El racionalismo educativo de A Plebe implicó la ruptura con las "lllusoes chimericas" (A PLEBE, nºxtraordinario, 22/11/1919), y destacó la acción como fundamento de la libertad. Así, la educación libertaria expuesta por el periódico se fundó en la acción guiada por "uma vontade suprema". (A PLEBE, nº extraordinario, 22/11/1919). La educación fue

\footnotetext{
13 Recordemos que $A$ Plebe surge como remplazo del periódico anticlerical $A$ Lanterna, cuyo surgimiento obedeció al movimiento nacional e internacional de indignación por el fusilamiento de Ferrer. (A PLEBE, n 1,09/06/1917).
} 
una apuesta a la construcción de libertad, que rompiera con las falsas ideologías pasionales que no permitían ver con claridad el devenir histórico. Para los colaboradores de A Plebe la muestra de racionalidad máxima se encontraba en los acontecimientos que alumbraron su coyuntura histórica.

Percepción a la que se sumó el sentido visionario de la ideología libertaria que hizo posible el desdoblamiento educativo en las páginas del periódico. De este modo, educarse en libertad implicaba comprender y construir el futuro venidero. De manera didáctica y táctica el periódico incorporó en su cuerpo frases cortas y contundentes:

Operário!.... O maior inimigo do progresso e da sciencia, é o Padre, porque a vida da Egreja pereclita perente a Luz da verdade, originaria do progresso e da sciencia [...] (A PLEBE, nº extraordinário, 22/11/1919).

La educación libertaria promulgada por la prensa popular y radical insistió en educar para el futuro, en contra de la educación tradicional que pretendía reproducir el statu quo. De este modo, al extrapolar los sentidos de las palabras y de las interpretaciones, el lector del presente puede observar, en estos indicios del pasado que son los periódicos, una muestra progresiva de la educación crítica y libertaria que llegó hasta nosotros. La educación como un acto político implicó que los sectores populares se asumieran como hombres conscientes de su humanidad y su papel en el avance social.

Pero, además, fue una educación basada en la acción. En el discurso defendido por A Plebe la educación y toma de conciencia eran el paso fundamental para romper con la retórica y fijar la mirada sobre los hechos. En ese sentido la relación entre enseñanza y aprendizaje, como generación efectiva de conocimiento, propuso una reflexión-acción desde lo concreto. La verdad que debía ser aprehendida se encontraba más allá de lo ideológico - entendido como superestructura - para posarse en el devenir concreto de los hechos históricos. En el devenir social de la estructura. Al respecto sostuvieron:

[...] Passou-se a época dos discursos e chegou a hora dos factos. Quem possue raciocínio e não vive na lua, deve confessar a si mesmo que os factos, na sua maturação, exigem uma concepção positiva do que se deve fazer. (A PLEBE, $n^{\circ} 06$, 29/03/1919).

Así, la educación racionalista que fue proclamada asumió que la enseñanza y el aprendizaje debían centrarse en las formas como los sujetos veían y asumían los hechos que experimentaban. De este modo, el hecho de existir como sujetos explotados provocó que para los lectores y estudiantes de las Escuelas Modernas ${ }^{14}$ el conocimiento solo fuera posible a partir de la condición emancipadora que ofrecía el estudio de su realidad. Del mismo modo, la ciencia era ciencia en tanto explicaba racionalmente dicha realidad, lo que determinaba la posibilidad de libertad de los sujetos gracias al devenir de los acontecimientos que en ese momento experimentaba el mundo. La ciencia era una ciencia positiva en su sentido de contribución al progreso social y a la emancipación popular.

Por otro lado, un aspecto que se debe tener en cuenta en la perspectiva educativa

\footnotetext{
${ }^{14}$ A Plebe constantemente promulgó e incentivo la creación de escuelas modernas y escuelas nocturnas, que hicieran posible la formación de los sectores populares, tanto de los niños como de los adultos. Estos centros educativos se guiaron bajo los preceptos de la educación racionalista promovida por Ferrer y los grupos anarquistas.
} 
expuesta por $A$ Plebe es el papel que jugó la visión de los inmigrantes. Entre 1890 y 1929 ingresaron al territorio brasilero algo más de 3'523.591 inmigrantes europeos, siendo en su mayoría italianos (1'156.472), portugueses (1'030.666) y españoles (551.385). (SCHORER, 1995, p. 100). Algunos de estos inmigrantes ya habían tenido algún contacto con ideas libertarias y al llegar a Brasil participaron en la redacción de periódicos radicales como $A$ Plebe.

Este fenómeno enriqueció las perspectivas educativas en tanto que se comprendió que las visiones del mundo eran plurales, y que por lo tanto debían ser respetadas en el entramado de las idiosincrasias nacionales. De ahí que, para la época, muchos periódicos radicales de Brasil fueran escritos en italiano y alemán, demostrando una hermandad y unión cosmopolita. $Y$ en ese mismo principio de unidad fraterna, algunos importantes líderes e intelectuales populares extranjeros impulsaron desde $A$ Plebe la necesidad de constituir una educación basada en la unión impuesta por los fines. La educación debería superar las fronteras ideológicas y desplegar sus objetivos formativos en la revolución futura. (A PLEBE, $n^{\circ}$ 06, 29/03/1919).

En un contexto más conservador y provinciano, signado, como ya fue descrito, por las pugnas partidistas, las pasiones religiosas y la indiferencia hacia la cuestión social por parte del Estado y las elites colombianas, La Humanidad desplegó un discurso educativo que privilegió la formación de una cultura obrero-popular autónoma y democrática. A diferencia de $A$ Plebe, los redactores de La Humanidad fueron más explícitos a la hora de hablar de una educación para los sectores populares, lo que los llevo a proponer una serie de artículos titulados "La educación de la Clase", en los cuales se intentó promover algunas prácticas educativas que hicieron posible la autonomía y organización obrera y popular.

Estos artículos aparecieron al interior de una sección denominada "Feminas", escrita por una mujer bajo el seudónimo de Clara Luna. Esta particularidad permite demostrar que, por lo menos al interior del campo de la izquierda, el discurso educativo, más relacionado a la formación moral que científica, contó con una participación activa de la mujer. Así, en el marco de una formación que asumió la constitución de un nuevo sujeto moralmente más humano o humanizado, el papel de la mujer fue asumido como el de orientadora. Fenómeno que replicó lo que sucedió en el plano de la movilización social con la figura de María Cano ${ }^{15}$.

A diferencia de la educación racional propuesta por $A$ Plebe, centrada en la ciencia de los hechos, La Humanidad promovió una educación que pretendió controlar las pasiones políticas y religiosas con un discurso moralizante y direccionado. Además, se partió de una premisa inicial, y fue la distinción entre líderes dirigentes y los dirigidos. Así, se propuso un método educativo "útil al proletariado ignaro y al que no lo es". (LA HUMANIDAD, no 47, 29/05/1926). Esta división obedeció a la estructura que ofrecía la párvula organización popular, así como a la intencionalidad, consciente o no, de formar orgánicamente a los cuadros dirigentes. De esta forma, la educción debía ser diferente para dirigentes y dirigidos ya que, según el periódico, sobre los primeros "[...] pesa la responsabilidad más definida: pues que siendo por voluntad, orientadora de grandes multitudes, necesita una preparación especial". (LA HUMANIDAD, № 47, 29/05/1926).

\footnotetext{
15 María Cano fue una líder revolucionaria colombiana de la década de los veinte, cuyo accionar se convirtió en un icono de resistencia para los sectores populares de la época. (MORENO, 2016).
} 
Sin embargo, la distinción al interior del proceso educativo propuesto por "Clara Luna" contiene una importante dialéctica que le da sentido y rompe las lógicas de poder inmersa en la relación orientadores-orientados. En la propuesta la educación popular es concebida como un proceso formativo gradual que buscaba "[...] una acción integral". (LA HUMANIDAD, no 47, 29/05/1926). De este modo, la diada orientadores-orientados fue emplazada en la dialéctica implícita de la relación teoría-práctica, y dentro de este desplazamiento se propuso que los dirigidos debían ser educados en "[...] estudios elementales que le formen el espíritu de clase y el concepto de lucha", haciendo una referencia más o menos clara al sentido de la práctica como acción social consciente. Por otro lado, el reducido número de dirigentes debía recibir una educación que los "adoctrine en los principios de su filosofía" (LA HUMANIDAD, ํo 47, 29/05/1926), refiriéndose al conocimiento reflexivo de los objetivos emancipadores. No obstante, la posición de los líderes, quienes debían estudiar los preceptos teóricos, no se reduce a la contemplación reflexiva, la dialéctica educativa propuesta consiste en que dicho líder "ilustrado" debe convertirse en mediador entre las teorías aprehendidas y los sectores de base. El líder debía fungir como una especie de traductor ya que

[...] el trabajador que ignora la existencia de los grandes tratadistas de nuestro Derecho de CLASE, perderá el tiempo, y quizás la esperanza de su emancipación en las arideces de un libro de Marx, pero no sucedería lo mismo si ponemos en sus manos un libro de sencillas lecciones escrito para su capacidad. (LA HUMANIDAD, no $47,29 / 05 / 1926$ ).

La realización de ese "libro de sencillas lecciones" era la tarea de los líderes, de ahí la necesidad de que recibieran una educación diferente.

De esta idea inicial sobre el acto educativo es posible identificar una preocupación constante en las líneas del periódico y entre sus redactores. Desde el comienzo siempre estuvo en el aire la intención de des-complejizar el discurso. Preocupación que puede ser desplazada al terreno de lo didáctico. A diferencia de la racionalidad teórica con la cual fue concebido el discurso libertario del campo de la izquierda, o debido precisamente a dicha racionalidad y complejidad, La Humanidad, y la acción misma de los líderes populares, se centró en la elaboración de estrategias didácticas que permitieran una relación de enseñanza y/o aprendizaje más fácil. De ahí que en las páginas del periódico sea posible encontrar la proposición de una educación diferenciada, pero complementaria, entre dirigentes y dirigidos; la determinación del papel del dirigente letrado como mediador entre sujeto, el conocimiento y la lectura de su realidad, al estilo de un intelectual orgánico capaz de dar sentido al bloque histórico del cual surge; y, el uso constante de la movilidad del sujeto mediador en la forma de profeta ${ }^{16}$.

Bajo esta perspectiva, una de las primeras lecciones pretendió instalar una práctica concreta entre los líderes populares. Según el texto

[...] la ala dirigente debe seleccionar expositores, es decir, obreros que lleven la buena nueva a todos los rincones de la tierra, que digan al grueso de las masas las

\footnotetext{
${ }^{16}$ Ejemplo de esto son las giras políticas realizadas por los líderes populares durante las décadas del veinte. Las giras políticas consistieron en el desplazamiento de los líderes de izquierda por el territorio nacional, con el fin de llevar el verbo revolucionario a todos los obreros y clases populares del país.
} 
leyes de la gravitación humana de modo tan consciente que puedan saber los más ignaros el fin del dominio capitalista [...] (LA HUMANIDAD, no 48, 05/06/1926).

Al interior de esta cita se encuentra, en primer lugar, un sentido religioso, como ya dijimos, profético en el cual los líderes se asumieron como redentores sociales. En segundo lugar, el sentido de la frase "de modo tan consciente" remite a la preocupación didáctica de la cual hablamos más arriba. Los oradores debían "seguir a Aristóteles, sobre todo en su primera clasificación, es decir en el género demostrativo”. (LA HUMANIDAD, n 48, 05/06/1926). En sentido didáctico se debía luchar contra los discursos barrocos que pretendían mostrar una falsa erudición, para favorecer una "sencilla actitud de maestros". (LA HUMANIDAD, nำ48, 05/06/1926). Así, se debía articular un discurso comprensible, con una didáctica basada en el uso de palabras claras y sencillas.

[...] Las masas necesitan las formas y las palabras más claras y sencillas, y la elocuencia gana más con la verdad que con la mentira [...] (LA HUMANIDAD, nำ 48, 05/06/1926).

Existió, pues, una preocupación educativa y didáctica que partió del principio de carencia. La educación, según el discurso expuesto por La Humanidad debía suplir un vacío. Debía completar al ser humano, ya que las masas estaban inmersas en una profunda ignorancia. Esta concepción permite entablar una relación entre la carencia, la didáctica y la religiosidad propia del entramado cultural colombiano. La didáctica (asumida como discurso práctico, no teórico) fue apropiada debido a una religiosidad que implicaba la obediencia, el paternalismo, la fe y el sacrificio. Así, la reinvención moral del obrero se constituyó bajo la senda de un cristianismo revolucionario camuflado.

Por otro lado, la educación fue asumida como un mecanismo para eliminar los odios entre el pueblo. A partir de la racionalización de las pasiones y de la eliminación de los vicios. La educación era "[...] uno de los medios de precaver las agitaciones y desterrar el odio de los pobres contra los mismos pobres [...]" (LA HUMANIDAD, no 21, 03/10/1925). Así, en la división propuesta, la educación de las bases, de los "ignaros", fue asumida como una educación moral que debía "suavizar" las costumbres en pro del progreso social.

En el mismo sentido, el periódico hizo llamados para que las elites asumieran que "el hombre no es meramente corpóreo; es inteligente". (LA HUMANIDAD, nํ 21, 03/10/1925). La educación popular propuesta por los redactores del periódico partió de la aceptación de que los hombres eran inteligentes. Los hombres eran susceptibles a ser educados y perfeccionarse. Aunque esta afirmación parezca evidente, en la época, la idea de mejora y perfeccionamiento estaba fuertemente ligada al estatus de los sujetos. Muestra de esto es que para las elites los sectores populares y obreros eran simples maquinas sin corazón ni razón. (LA HUMANIDAD, nº 21, 03/10/1925).

Finalmente, la educación de los sectores populares expuesta por La Humanidad pretendió formar para la autonomía. De esta manera, la formación que se impartió en las líneas del periódico y en la contingencia de las huelgas, se basó en la constitución de una conciencia obrera y popular llena de autonomía y capaz de autogobernarse. (LA HUMANIDAD, $\mathrm{n}^{\circ}$ 51, 26/06/1926). El discurso educativo, en el párvulo campo de la izquierda colombiana siguió un horizonte con múltiples puntos de fuga. La fe, la disciplina, el mejoramiento moral, la lucha social y la resistencia, fueron mecanismos que impulsaron las prácticas pedagógicas de los sectores populares. 


\section{Conclusión}

El estudio de los discursos educativos implícitos y explícitos en los medios de comunicación escrita de tendencia radical de izquierda, durante los primeros años del siglo $\mathrm{XX}$, implica la puesta en marcha de un sin número de problemas metodológicos que probablemente no fueron superados por este texto. En primer lugar, se debe advertir que las intencionalidades educativas son capaces de transgredir los discursos explícitos y posarse en sutiles ejercicios prácticos que se escapan a la mirada del historiador. De este modo, en el caso de A Plebe, por ejemplo, más que haber ofrecido un discurso educativo secuencial y metódicamente expedito, la intencionalidad educativa de sus redactores debe ser advertida en la forma misma del periódico, en el uso abundante de las imágenes, en la utilización continua de frases cortar y contundentes, en la preocupación por instituir centros formativos para los sectores populares, además de la constante invitación a la lectura. Estas son prácticas que incitan a imaginar una idea educativa pero no única, en la que primó el racionalismo y la formación política. Por el contrario, hay periódicos como La Humanidad en los que se acciona de manera directa un discurso educativo con intencionalidades de organización pragmática, pero que no dejan de ocultar intencionalidades que van más allá de lo formativo. Un discurso que aparenta encarnar un principio religioso de catequesis seguido por la peregrinación de los líderes profetas. No obstante, caer en este tipo de definición vaciaría el ejercicio de acercamiento histórico.

A estas problemáticas del estudio histórico se pueden sumar otras que no es menester atender aquí, pero esta última referencia nos permite abordar algunos puntos conclusivos del estudio, a partir de las lógicas de la distinción que permiten los estudios comparados como el que propusieron estas páginas. Centrándonos en los discursos educativos ofrecidos por dos periódicos radicales, ubicados en dos contextos relativamente lejanos, podemos encontrar algunas lógicas de desenvolvimiento. (KOCKA, 2003).

a) A Plebe asumió la educación como un mecanismo de acción y racionalización basada en el devenir de los acontecimientos históricos. En esta medida, la educación fue un ejercicio pragmático sobre la lectura de la realidad. Esta particularidad podría ser explicada a partir del papel que jugaron los inmigrantes en la constitución del discurso de izquierda al interior de los sectores populares brasileros, especialmente en la ciudad de São Paulo -el caso que aquí se aborda. A partir de una mirada cosmopolita de la realidad, además de las noticias de primera mano que se tenían sobre los acontecimientos que se sucedían en Europa, A Plebe agenció un discurso en el que se desarrolló una rica filosofía de la historia que apuntó su mirada en el futuro.

b) El sentido de lucha y construcción del futuro, implicó una "educación para el futuro". La educación popular implicó una filosofía de la historia en la cual el devenir de las acciones estuvo signado por la razón, entendida como libertad, como eliminación del Estado y como supresión de los valores religiosos. En la misma línea, una educación para el futuro significó la proposición de una educación como acto político liberador, dentro de la cual el hombre era un sujeto histórico. Un sujeto capaz de construir su historia.

c) Esta idea precede a un sentido que es muy utilizado por los pedagogos modernos, y que consiste en que el aprendizaje debe ser significativo. Aunque la forma de esta proposición fue diferente. El discurso educativo de A Plebe, de manera implícita, se basó en la experiencia existencial como medio de conocimiento. Los hombres aprenden a partir de su experiencia con el mundo que los rodea, de ahí que la ciencia fuera una ciencia 
de los hechos.

d) Esta última reflexión nos llevó a preguntarnos por el objeto sustancial de la relación de enseñanza y/o aprendizaje que movilizó los discursos, en este caso, de los dos periódicos de izquierda. Si bien las respuestas pueden ser múltiples, se puede concordar en que los dos periódicos agenciaron la idea de enseñanza y aprendizaje de la realidad jalonada por la condición emancipadora del ejercicio educativo. La realidad es el objeto a aprehender, sin importar los medios didácticos y las múltiples visiones que pasan sobre él.

e) Teniendo como base la aprehensión de la realidad, la principal distinción entre La Humanidad y A Plebe, consistió en la manera como definieron el acercamiento a lo educativo. La Humanidad se centró en el desarrollo de prácticas didácticas que facilitaran el acto de comprensión para los sectores populares, quienes eran vistos como masas irracionales y viciosas. De esta manera, y recurriendo al uso de un lenguaje religioso, el periódico desarrollo una didáctica comprensiva que pretendió respetar la cosmovisión de las masas, sin olvidar la formación teórica que debían tener los cuadros dirigentes. A Plebe sustentó su discurso educativo en un problema que ubicamos en la constitución de una filosofía de la historia. La preocupación educativa fue por el fin último de la acción revolucionaria. Se debía educar a las masas para construir y afrontar un futuro revolucionario que llegaría inevitablemente, como lo demostraban los hechos.

f) Finalmente el discurso educativo expuesto por los periódicos se basó en una dialéctica empujada por el imaginario de la utopía. De este modo, el binomio enseñanzaaprendizaje descargó sus intencionalidades en el movimiento de las relaciones reflexiónacción y práctica-teoría con el fin de alcanzar la revolución social vía la construcción de una cultura popular y de un hombre nuevo. Educarse era reflexionar sobre la realidad vivida, sobre la existencia del sujeto explotado, como un singular colectivo que encarnaba todas las dificultades de un sistema precario y selectivo.

\section{Referencias}

AGUILERA, Mario; VEGA, Renán. Ideal democrático y revuelta popular. Bogotá: Cerec. 1998.

A PLEBE. [Entre 1917 y 1920]. São Paulo: Arquivo Edgard Leuenroth.

ARCHILA, Mauricio. La Humanidad, el periódico obrero de los años veinte. Boletín cultural y bibliográfico, v. 22, n. 3, p. 19-33, 1985.

CARBÓ, Posada Eduardo. Los límites del poder: elecciones bajo la hegemonía conservadora, I886-1930. Boletín cultural y bibliográfico, Bogotá, v. 39, n. 60, 2002.

CARDOSO, Fernando Henrique. Dos governos militares a Prudente - Campos Sales. In FAUSTO, Boris (Dir.). História geral da civilização brasileira III: o Brasil Republicano 1. Estrutura de poder e economia (1889-1930). Rio de Janeiro: Editora Bertrand Brasil S. A., 1989.

CARONE, Edgard. A República Velha I (instituições e classes sociais). São Paulo: Difel, 1975.

CARVALHO, Jose Murilho de. Mandonismo, Coronelismo, Clientelismo: uma discussão conceitual. Dados [online], Rio de Janeiro, v. 40, n. 2, 1997.

DARNTON, Robert. El beso de Lamurette: reflexiones sobre historia cultural. Buenos Aires: Fondo de Cultura Económica, 2010. 
FAUSTO, Boris (Dir.). História geral da civilização brasileira III: o Brasil Republicano 1. Estrutura de poder e economia (1889-1930). Rio de Janeiro: Editora Bertrand Brasil S. A., 1989.

FREIRE, Paulo. Pedagogía de la indignación. Madrid: Morata, 2001.

GIROUX, Henry. Los profesores como intelectuales. Paidos: Barcelona, 1990.

GONÇALVES, Ody F. Trajetória e ação educativa do jornal A Plebe (1917-1927).

Quaestio: revista de estudos em educação, v. 6, nํ2, 2004.

KOCKA, Jürgen. Comparison and beyond. History and theory, v. 42, n. 1, p. 39-44, feb. 2003.

LEAL, Victor Nunes. O Coronelismo e o Coronelismo de cada um. Dados, v. 23, n. 1, p. 11-14, 1980.

Coronelismo, enxada e voto. Rio de Janeiro: Forense, 1948.

LEUENROTH, Edgar. NEGRO, Helio. O que é o Maximismo ou Bolcheviquismo. São Paulo: Editora Semente.198? [1919].

MEDINA, Gallego Carlo. Una propuesta para la periodización de la historia del conflicto colombiano en el siglo XX. In: GUERRERO BARON, Javier; ACUÑA RODRIGUEZ, Olga (Comps.). Para reescribir el siglo XX: Memoria, insurgencia, paramilitarismo y narcotráfico. Medellín: La Carreta Editores, UPTC, 2011.

MELO, Jorge Orlando. La Republica conservadora. In: MELO, Jorge Orlando (Coord.). Colombia hoy. Bogotá: Presidencia de la Republica, 1996. p. 43-95.

MORENO, Eduard. Contextos distantes, ideas compartidas: una historia comparada sobre la apropiación de las ideas de izquierda (Colombia y Brasil: 1886-1930). 2017. Tese (Doutorado em História) - Pontifícia Universidade Católica do Rio Grande do Sul, Porto Alegre, 2017.

. María Cano: escritura y revolución. Revista Huellas, v. 99, p. 20-29, 2016.

NúÑEZ, Luz Ángela. El obrero ilustrado: prensa obrera y popular en Colombia 19091924. Bogotá: Uniandes-Ceso. 2006.

LA HUMANIDAD. [Entre 1925 y 1927] Cali: Biblioteca Nacional de Colombia

QUEIROZ, Isaura Pereira de. O Coronelismo numa interpretação sociológica. In:

FAUSTO, Boris (Dir.). História da civilização brasileira III: O Brasil Republicano 1.

Estrutura de poder e economia (1889-1930). Rio de Janeiro: Editora Bertrand Brasil S. A., 1989. p. 153-192.

SANTOS, Kauan Willian. O jornal A Plebe: militância e estratégias de propaganda anarquista no movimento operário em São Paulo (1917-1920). 2013. Monografia (Bacharelado e Licenciatura em História) - Universidade Federal de São Paulo, Guarulhos, 2013.

SCHORER, Petrone Maria Tereza. Imigração. In: FAUSTO, Boris (Dir.). História da civilização brasileira III: O Brasil Republicano 2. Sociedade e instituições (1889-1930). Rio de Janeiro: Bertrand Brasil, 1985.

SEWELL JR., William H. Marc Bloch and the logic of comparative history. History and theory, v. 6, n. 2, p. 208-218, 1967.

SUNKEL, Guillermo. La representación del pueblo en los diarios de masas. Diálogos de la comunicación, n. 17, 1987.

TIRADO, Mejía Álvaro. Colombia: Siglo y medio de Bipartidismo. In: MELO, Jorge Orlando 
(Coord.). Colombia hoy. Bogotá: Presidencia de la Republica, 1996.

WIRTH, John. Minas e a nação. um Estado de poder e dependência regional 1889-1937. In: FAUSTO, Boris (Dir.). História geral da civilização brasileira III: O Brasil

Republicano 1. Estrutura de poder e economia (1889-1930). Rio de Janeiro: Editora Bertrand Brasil S. A., 1989.

EDUARD ESTEBAN MORENO TRUJILLO es licenciado en Ciencias Sociales, magister en Historia de la Universidad de los Andes y doctor en Historia de la Pontifícia Universidade Católica do Rio Grande do Sul (PUC-RS). En la actualidad es docente-investigador de la Maestría en Educación de la Universidad La Gran Colombia (Bogotá/Colombia).

Dirección: Carrera 5, 12b - 49, Bogotá, Colombia.

E-mail: eduard.moreno@ugc.edu.co

Recebido em 15 de agosto de 2017.

Aceito em 26 de junho de 2018. 